\title{
EXPERIÊNCIAS COM O ENSINO REMOTO E OS EFEITOS NO INTERESSE E NA SATISFAÇÃO DOS ESTUDANTES DE CIÊNCIAS CONTÁBEIS DURANTE A PANDEMIA DA SARS-COV-2
}

\author{
EXPERIENCES WITH REMOTE TEACHING AND EFFECTS ON STUDENT INTEREST AND \\ SATISFACTION OF STUDENTS IN ACCOUNTING SCIENCES DURING THE SARS-COV-2 \\ PANDEMIC
}

\author{
EDICREIA ANDRADE DOS SANTOS \\ Professora na Universidade Federal do Paraná (UFPR) \\ Doutora em Contabilidade pela Universidade Federal de Santa Catarina (UFSC) \\ Orcid: http://orcid.org/0000-0001-8745-3579 / E-mail: edicreiaandrade@yahoo.com.br \\ Av. Prefeito Lothário Meissner, 632 - Campus III - Jardim Botânico - CEP: 80.210-170 - Curitiba - PR
}

\section{GIULIO HENRIQUE FURLAN DE CAMPOS}

Universidade Federal do Paraná - UFPR

Graduando em Ciências Contábeis na Universidade Federal do Paraná (UFPR)

Orcid: https://orcid.org/0000-0001-5770-2343 / E-mail: ghfc298@gmail.com

\section{JONATAS DUTRA SALLABERRY}

Doutorando em Contabilidade

Universidade Federal de Santa Catarina (UFSC) e Universidad de Murcia (UMU)

Orcid: https://orcid.org/0000-0001-7492-727X / E-mail: jonatas.sallaberry@hotmail.com

\author{
LUIZ MIGUEL RENDA DOS SANTOS \\ Universidade Federal do Mato Grosso do Sul \\ Doutor em Financiación e Investigación Comercial pela Universidad Autonoma de Madrid (Espanha) \\ Orcid: https://orcid.org/0000-0003-2447-9258 / E-mail: luiz.renda@ufms.br
}

Submissão: 07/08/2020. Revisão: 13/10/2020. Aceite: 05/11/2020. Publicação: 29/12/2020.

DOI: http://dx.doi.org/10.22277/rgo.v14i1.5711

\section{RESUMO}

O isolamento social, decorrente do enfrentamento ao contágio do novo Coronavírus (SARSCoV-2), gerou muitas transformações nos processos de trabalho e no ensino. Este estudo investiga as experiências dos estudantes de Ciências Contábeis com o ensino remoto implementado por uma instituição de ensino superior federal da região centro-oeste brasileira durante a pandemia da SARS-CoV-2, e os efeitos no seu interesse e na sua satisfação com as aulas. A amostra compreendeu 102 estudantes, que responderam a um questionário com perguntas fechadas e abertas, cujos dados foram tratados com as técnicas de Equações Estruturais e de Análise de Conteúdo. Os resultados evidenciaram que é preciso que os professores busquem diferentes metodologias de ensino e distintas tecnologias de informação e comunicação (TICs) para reproduzir uma aula presencial em um ambiente virtual de aprendizagem e para que o aluno tenha maior interesse e satisfação. Ademais, foi identificado que a maioria dos estudantes desconhecia o funcionamento da dinâmica da modalidade de ensino remoto, o que gerou inúmeras dúvidas e receios, e refletiu nas experiências deles com as interações entre professor-aluno e aluno-aluno, as quais interferem significativamente no processo de aprendizagem, logo, no interesse e na satisfação do aluno.

Palavras-chave: Ensino remoto. Interação professor-aluno. Interação aluno-aluno. 
Experiências com o ensino remoto e os efeitos no interesse e na satisfação dos estudantes de Ciências Contábeis durante a pandemia da SARS-CoV-2

\begin{abstract}
Social isolation, resulting from coping with the contagion of the new Coronavirus (SARS-CoV2 ), has generated many changes in work processes and teaching. This study investigates the experiences of Accounting students with remote education implemented by a federal higher education institution in the Brazilian Midwest region during the SARS-CoV-2 pandemic, and the effects on their interest and satisfaction with the classes. The sample comprised 102 students, who answered the questionnaire with closed and open questions, whose data were treated with the techniques of Structural Equations and Content Analysis. The results showed that it is necessary for teachers to seek different teaching methodologies and different information and communication technologies (ICTs) to reproduce a face-to-face class in a virtual learning environment and for the student to have greater interest and satisfaction. Furthermore, it was identified that most students were unaware of the dynamics of the remote teaching modality, which generated numerous doubts and fears, and reflected in their experiences with the interactions between teacher-student and student-student, which significantly interfere in the learning process, therefore, in the interest and satisfaction of the student.
\end{abstract}

Keywords: Remote education. Teacher-student interaction. Student-student interaction.

\title{
1 INTRODUÇÃO
}

No início de março de 2020, a Organização Mundial de Saúde (OMS) classificou como pandemia a doença causada pelo novo Coronavírus (SARS-CoV-2), a qual exige medidas de isolamento social devido à sua acelerada disseminação (DENG; PENG, 2020). Com isso, ocorreu a suspensão das aulas presenciais, e um sem número de escolas e instituições de ensino superior (IES) recorreram ao ensino remoto para tentar prosseguir com o ano letivo (SANTOS JUNIOR; MONTEIRO, 2020). A mudança exigiu adaptação rápida por parte dos professores e dos estudantes.

Diversos casos em todo o mundo auxiliam no entendimento a respeito de como proceder diante da impossibilidade de estudar presencialmente. $\mathrm{Na}$ China, país de origem do novo Coronavírus, as atividades presenciais do semestre de verão foram canceladas com a finalidade de conter os índices de contágio. Na França, os lycees, que trabalham com crianças com idade entre 11 e 18 anos, depararam-se com o retorno condicionado ao uso de máscaras para proteção individual. Em Nova York (Estados Unidos), foram distribuídos tablets e laptops com o intuito de fornecer instrumentos para estudantes de baixa renda assistirem às aulas (NEWS WIRES, 2020; KOLOGRIVAYA; SHLEIFER, 2020; WATSON; THOMPSON, 2020). No Brasil, logo após o anúncio da OMS, o Ministério da Educação e Cultura (MEC) publicou a portaria de n. 343/2020, que autorizou a utilização de meios e tecnologias digitais para a substituição temporária das aulas presenciais em IES (SANTOS JUNIOR; MONTEIRO, 2020).

Contingências como a pandemia do novo Coronavírus refletem a importância de se entender diversas situações, como: (i) os desafios do ensino remoto, o modo de os professores adaptarem os conteúdos, as dinâmicas de sala, as aulas expositivas, as avaliações etc.; (ii) a maneira de manter os estudantes interessados e engajados com as aulas e com o curso; e, por fim, (iii) as percepções e as experiências dos estudantes a respeito do ensino remoto e/ou a distância. É acerca do entendimento da terceira direção que este estudo se debruça, almejando responder a seguinte questão: quais os efeitos da experiência dos estudantes com as características do ensino remoto implementado por uma IES durante a pandemia? Assim, 
Edicreia Andrade dos Santos, Giulio Henrique Furlan de Campos, Jonatas Dutra Sallaberry e Luiz Miguel Renda dos Santos

o objetivo central é analisar as experiências dos estudantes de Ciências Contábeis com o ensino remoto implementadas por uma IES federal da região centro-oeste brasileira durante a pandemia da SARS-CoV-2, e seus efeitos no interesse e na satisfação deles com as aulas.

Este estudo justifica-se pela necessidade de entender as problemáticas no aprendizado de estudantes com uso do ensino remoto praticado durante a pandemia, o qual está incluído dentro da configuração do ensino a distância $(E a D)$ devido ao enfoque que se refere a uma educação mediada pela tecnologia, mas seguindo os princípios da educação presencial. Essa medida foi tomada em resposta a uma situação inesperada, pois, em âmbito federal, não existia um plano de contingência educacional ou administrativo para casos como este, e grande parcela das instituições de ensino brasileiras de todos os níveis (básico, fundamental e superior) não estava preparada para isso. Por conseguinte, sabe-se que situações de conflito ou de redução da integração do discente com o professor e a IES, como a causada pelo novo Coronavírus, podem acarretar a evasão do aluno (COSTA; GOUVEIA, 2018).

Nesse contexto, é fundamental investigar o que o aluno pensa e quais são os níveis de satisfação (PASWAN; YOUNG, 2002) com a conjuntura em que se encontra, posto que a essência da universidade pública é formar profissionais qualificados com os recursos oriundos da população. A satisfação dos estudantes é crucial, uma vez que o nível desta impacta diretamente a qualidade da formação do profissional e, consequentemente, a atuação deste na sociedade (VIEIRA; MILACH; HUPPES, 2008).

\section{REFERENCIAL TEÓRICO}

\subsection{ENSINO E-LEARNING}

E-learning significa ensino eletrônico, e essa técnica se apoia na tecnologia de informação e comunicação (TICS) para oferecer estudo de forma não presencial, ou seja, com aulas mediadas por tecnologias digitais (PAECHTER; MAIER; MACHER, 2010). Esse ensino pode ser conduzido de duas maneiras: (i) de forma simultânea ou síncrona, com um professor conectado à internet ministrando a aula no mesmo momento em que o aluno a assiste; ou (ii) de forma não instantânea ou assíncrona, isto é, a partir de um conteúdo gravado e disponibilizado aos estudantes (SANTOS JUNIOR; MONTEIRO, 2020).

Dessa forma, o e-learning proporciona que os estudantes tenham acesso aos conteúdos online, em um ambiente bem diferente das salas de aula tradicionais. De modo complementar, também é visto como um objeto de aprendizado que pouco altera o status quo pedagógico, enquanto, ao mesmo tempo, estudantes (ou e-learners) expressam preocupações com a gestão do tempo para o aprendizado e, ainda, da carga emocional ao se deparar com um novo ambiente de aprendizado (SHARPE; BENFIELD, 2005).

O e-learning é diferente do EaD por requerer o apoio de tutores de forma atemporal, carga horária diluída em diferentes recursos midiáticos e atividades síncronas e assíncronas. O Brasil vem, progressivamente, adaptando-se ao modelo EaD, seja ele total ou parcial. Inicialmente normatizada pela Portaria n. 9 4.059/2004 do MEC, foi possibilitada a introdução da modalidade semipresencial em $20 \%$ da organização curricular dos cursos superiores.

Em 2006, em caráter experimental, o MEC emitiu a Portaria n. 873/2006, com o intuito de estimular o acesso à educação em locais distantes e isolados por meio de cursos integralmente à distância (BRASIL, 2006). A esse despeito, argumenta-se que essas estratégias podem permitir uma maior adequação a momentos de contingências diversas, como greves (MORTARI, 2019), e de isolamento devido a pandemias, tal como a resultante do novo Coronavírus. 
Experiências com o ensino remoto e os efeitos no interesse e na satisfação dos estudantes de Ciências Contábeis durante a pandemia da SARS-CoV-2

As instituições de ensino, tanto de nível superior quanto básico, ainda são majoritariamente presenciais e com pouco uso de ferramentas de tecnologias digitais de informação e comunicação (TDICs). Porém, em 2020, em decorrência da pandemia da SARSCoV-2, instituições de 186 países decretaram fechamento de instituições de ensino na modalidade presencial, impactando 1.292.378.969 estudantes até o final do mês de abril, aproximadamente $90 \%$ da população mundial de estudantes (UNESCO, 2020). Diante desse cenário, o MEC autorizou a substituição de disciplinas presenciais por aulas no formato remoto por meio da utilização das TDICs (BRASIL, 2020).

Mudanças motivadas por contingências, como a pandemia de SARS-CoV-2, impulsionam a compreensão de diversos reflexos do ensino via e-learning. Nesse sentido, existem algumas características marcantes relacionadas com a experiência dos estudantes com a utilização do e-learning, entre elas: a preocupação com a gestão de tempo e os sentimentos concernentes aos estudos, como sentimentos de inspiração, com discussões e interações em grupo, marcados também pelo sentimento de frustração, decorrente de dificuldades técnicas ou de pontos de vista diferentes aos dos colegas (SHARPE; BENFIELD, 2005).

Contribuições como a de Abdous (2019) indicam que o despreparo no manuseio dos recursos tecnológicos resulta em aumento de ansiedade e em frustração das expectativas em relação ao curso. Assim, faz-se relevante entender melhor as experiências dos alunos, seu interesse enquanto estudante e sua satisfação com a condução do curso e das aulas em formato remoto.

\subsection{CARACTERÍSTICAS DE INTERESSE E SATISFAÇÃO DO ALUNO}

Diversos fatores relativos ao curso, aos professores, às disciplinas e às aulas podem refletir no interesse e na satisfação dos alunos. Detalhadamente, o interesse do estudante é entendido como a autoavaliação do indivíduo acerca da sua participação nas atividades propostas e disponíveis no curso, além da maneira como ele se enxerga e o modo como se dedica a aprender os conteúdos ministrados (PASWAN; YOUNG, 2002). Esse envolvimento acontece motivado por diversas estratégias e podem variar de acordo com o perfil do estudante (SILVA et al., 2019). Já a satisfação é um conceito multidimensional, pois abarca diferentes áreas da experiência acadêmica, e quando relacionada aos estudos pode influenciar seu envolvimento com a instituição, implicando o interesse de permanecer nela, ou não, em continuar com os estudos, ou não, entre outros comportamentos influenciáveis (GUERREIRO, 2011).

Dentre os inúmeros fatores que afetam o interesse e a satisfação dos estudantes, destacam-se os referentes às características de como o curso e as aulas são conduzidas, que, no conjunto, podem atingir também o desempenho dos alunos e os indicadores da IES (SOARES; BORDIN; ROSA, 2019). Ademais, ao observar a partir da perspectiva do ensino remoto (online), pode-se mencionar outros fatores como: (i) o desenho da disciplina/aula, o material de aprendizagem e o ambiente eletrônico; (ii) a interação professor-aluno; (iii) a interação aluno-aluno (entre colegas); (iv) os processos de aprendizagem individual; e (v) os resultados das disciplinas/aulas (PAECHTER; MAIER; MACHER, 2010).

$O$ desenho da disciplina e das aulas de um professor em um ambiente online engloba múltiplos aspectos do processo de aprendizado. Como exemplo, tem-se a própria introdução ao material e os dados técnicos do uso de alguma plataforma de ensino, passando pela didática e pelo suporte individualizado à utilização dos materiais, e, finalmente, as provas e as 
Edicreia Andrade dos Santos, Giulio Henrique Furlan de Campos, Jonatas Dutra Sallaberry e Luiz Miguel Renda dos Santos

demais formas de avaliação dos estudantes (EHLERS, 2004). No caso do ensino remoto, são enfatizados todos os meios que são usados para a aplicação do conteúdo (PAECHTER; MAIER; MACHER, 2010). A qualidade do ambiente de aprendizagem e a facilidade de utilização da plataforma também contribuem para o sucesso, a satisfação e o interesse do aluno (CHANG; TUNG, 2008; PAECHTER; MAIER; MACHER, 2010).

A partir do exposto, apresenta-se a seguinte hipótese:

$\mathrm{H}_{1}$ - As experiências do aluno com o desenho das disciplinas/aulas afetam positivamente (a) seu interesse enquanto estudante e (b) sua satisfação com a condução do curso.

A interação professor-aluno é considerada essencial pela maior parte dos estudantes e altamente desejável pela maioria dos professores (MOORE; KEARSLEY, 2007; PAECHTER; MAIER; MACHER, 2010). Além disso, em IES públicas, os professores possuem laços de maior confiança com seus coordenadores e fornecem maior independência aos estudantes (MEDEIROS; SIQUEIRA, 2019). Essas interações fazem menção às habilidades que o professor possui de transmitir o conteúdo ao aluno (PAECHTER; MAIER; MACHER, 2010), pois a sua perícia em relação ao uso dos instrumentos de e-learning pode ser uma variante significativa no que tange à aquisição de conhecimento e habilidades no processo de aprendizado.

Assim, propõe-se a seguinte hipótese:

$\mathrm{H}_{2}$ - As experiências do aluno com a interação professor-aluno afetam positivamente (a) seu interesse enquanto estudante e (b) sua satisfação com a condução do curso.

A interação aluno-aluno, ou seja, entre colegas, promove o desenvolvimento de diferentes perspectivas e de pensamento crítico, pois possibilita o compartilhamento de ideias e conhecimento (ANDERSON, 2004). Nessa direção, Anderson (2004) argumenta que a interação é importante para a criação de comunidades de aprendizagem, e que leva o estudante a desenvolver habilidades interpessoais, como a habilidade de se comunicar e se relacionar com os outros. Ademais, essas interações acarretam sentimentos de inspiração, com discussões e interações em grupo, marcadas também pelo sentimento de frustração, decorrente de dificuldades técnicas ou pontos de vista diferentes aos dos colegas (SHARPE; BENFIELD, 2005). Conforme forem essas interações, maior pode ser o interesse do aluno e a sua satisfação com a condução do curso.

Com isso, descreve-se a seguinte hipótese:

$\mathrm{H}_{3}$ - As experiências do aluno com a interação aluno-aluno afetam positivamente (a) seu interesse enquanto estudante e (b) sua satisfação com a condução do curso.

Outro tipo de experiência destacado neste estudo é a relacionada aos processos de aprendizagem individual. Salienta-se que as modernas teorias de aprendizagem de qualquer paradigma cognitivo-construtivista assumem que a aprendizagem envolve processos interativos de estruturação, refinamento e reestruturação de modelos mentais (YADIN; OR$B A C H, 2019)$. Estes são combinados com outros processos de aprendizagem, como criação de sentido, depuração, avaliação, reflexão e muito mais (YADIN; OR-BACH, 2019). Desse modo, todos esses processos são necessários para uma aprendizagem significativa, tanto em um contexto de aprendizagem colaborativa quanto individual.

Os processos de aprendizagem individual permitem ao estudante tornar-se mais adaptado ao seu meio ou mais capaz de realizar uma tarefa ou, apenas, ainda mais consciente de algumas realidades. Em um ambiente de ensino remoto, os alunos podem perceber amplas oportunidades de praticar e aplicar o que estão aprendendo, além de ter escolhas quanto ao 
Experiências com o ensino remoto e os efeitos no interesse e na satisfação dos estudantes de Ciências Contábeis durante a pandemia da SARS-CoV-2

tempo, ao lugar e à regulamentação dos processos de aprendizagem (NARCISS; PROSKE; KÖRNDLE, 2007). De certo modo, essa autorregulação da aprendizagem é uma característica importante, que contribui para a motivação dos alunos (PINTRICH, 2000), o que permite conjecturar a seguinte hipótese:

$\mathrm{H}_{4}$ - As experiências do aluno com os processos de aprendizagem individual afetam positivamente (a) seu interesse enquanto estudante e (b) sua satisfação com a condução do curso.

Por fim, os resultados das disciplinas/aulas podem ser entendidos sob as perspectivas das variáveis cognitivas e emocionais. Perante a variável cognitiva, os resultados de aprendizagem são considerados os mais importantes, sendo relacionados a competências como conhecimento teórico e metódico, bem como a habilidades necessárias para resolução de problemas, a competências pessoais, sociais e/ou de mídia (PAECHTER; MAIER; MACHER, 2010). No entendimento das variáveis emocionais, um dos resultados é a satisfação com aulas, disciplina e/ou curso, e que influencia a decisão de continuar ou abandonar (LEVY, 2007).

Em linhas gerais, os resultados das disciplinas/aulas se referem aos benefícios percebidos pelo estudante, de modo que, entre estes, destacam-se o conhecimento útil, a resolução de problemas e as habilidades desenvolvidas com o uso de plataformas de $e$ learning ou com métodos de aprendizado, como a gestão do próprio tempo ou organização dos estudos (PAECHTER; MAIER; MACHER, 2010). Consequentemente, se esses resultados forem bons, também serão positivos os efeitos no interesse e na satisfação do aluno, o que permite apresentar a seguinte hipótese:

$\mathrm{H}_{5}$ - As experiências do aluno com os resultados das disciplinas/aulas afetam positivamente (a) seu interesse enquanto estudante e (b) sua satisfação com a condução do curso.

A suspensão das aulas tende a gerar menor desempenho dos estudantes (OLIVEIRA; GOMES; BARCELLOS, 2020), entretanto, mesmo a continuidade do calendário acadêmico, por meio de outras estratégias, pode causar outras dificuldades a docentes e discentes (DIAS; PINTO, 2020). Com base no exposto e nas hipóteses descritas, apresenta-se o desenho da pesquisa:
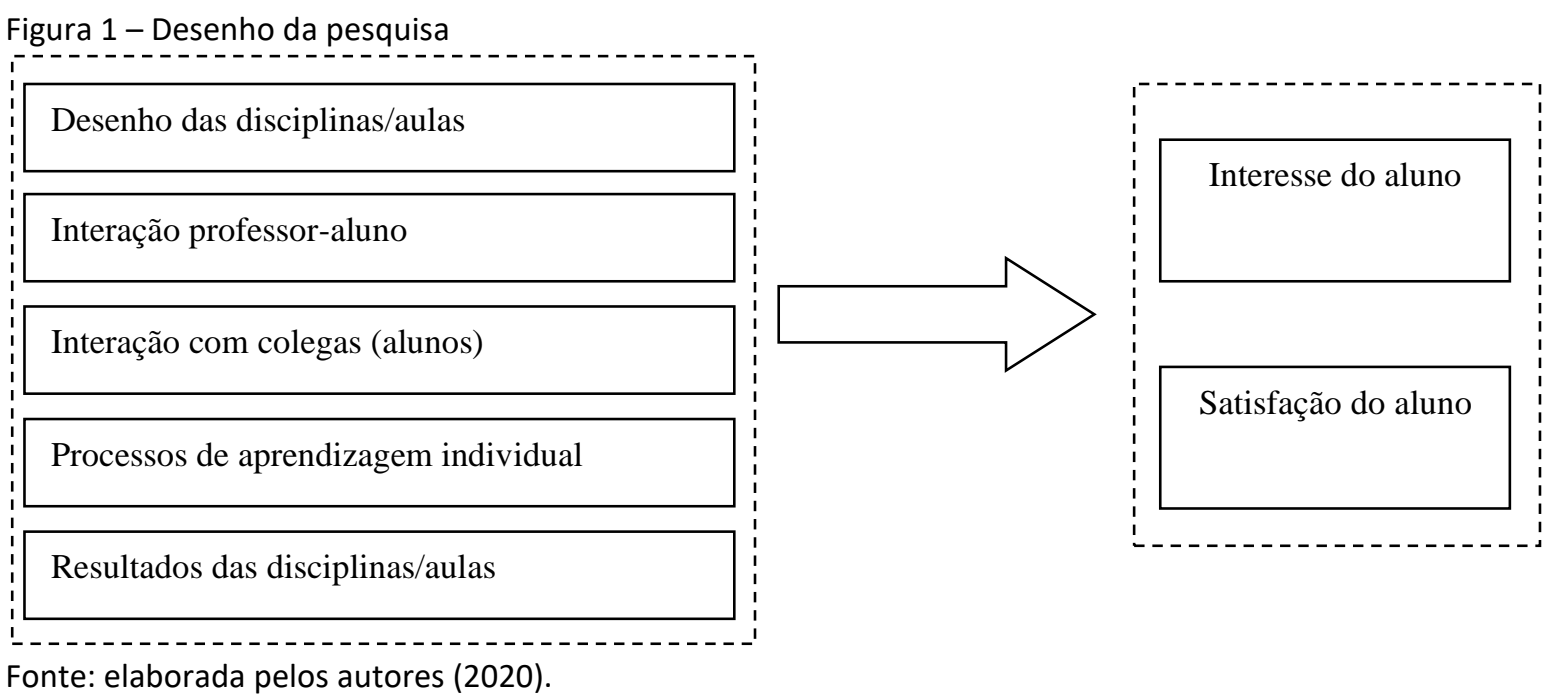
Edicreia Andrade dos Santos, Giulio Henrique Furlan de Campos, Jonatas Dutra Sallaberry e Luiz Miguel Renda dos Santos

A partir das relações evidenciadas na Figura 1, depreende-se que tanto o interesse do aluno quanto sua satisfação são influenciados pelas suas experiências com as características das disciplinas e das aulas ofertadas por intermédio do ensino remoto.

\section{PROCEDIMENTOS METODOLÓGICOS}

\subsection{AMOSTRA E INSTRUMENTO DE PESQUISA}

Esta pesquisa, de natureza quantitativa-qualitativa, busca investigar os efeitos da experiência dos estudantes com o ensino remoto implementado no curso de Ciências Contábeis em uma IES federal da região centro-oeste brasileira. Seu enfoque foi destinado às atividades de ensino durante a pandemia de SARS-CoV-2, com a utilização de estratégias de ensino adaptadas ao isolamento social preconizado pelos órgãos técnicos de saúde.

A população da pesquisa compreendeu todos os graduandos a partir do segundo período, devidamente matriculados no 1 ㅇ semestre letivo de 2020. A amostra foi constituída por 121 respondentes, no entanto, foi preciso excluir 19 respostas por não preencherem completamente o instrumento de pesquisa, o que resultou em uma amostra final de 102 respostas válidas. Vale ressaltar que previamente foi estabelecido como critério a participação de graduandos que estivessem cursando a partir do segundo semestre pelo fato de estarem socializados com a cultura e as estratégias tradicionais de ensino da instituição.

$O$ instrumento de pesquisa foi desenvolvido em formato online, na plataforma SurveyMonkey, e aplicado por um dos autores, professor da instituição, no ambiente virtual de aprendizagem (AVA), no período de 17 a 25 de abril de 2020. Para validar o tamanho da amostra necessária e o poder estatístico, a aplicação do software G*Power (FAUL; ERDFELDER; LANG, 2009), considerando o efeito total de cinco variáveis preditoras nas duas variáveis dependentes, ao nível de significância de 5\%, e um poder estatístico de 0,95, exigiu amostra mínima superior a 96 respostas válidas.

No instrumento foram listadas quatro questões de controle dos dados demográficos; os itens de questionamento de experiências e objetivos relacionados, nos sete construtos correspondentes às variáveis da pesquisa, listados no Quadro 1; e uma questão discursiva para reflexões e sugestões dos estudantes.

As variáveis explicativas do modelo são compostas dos construtos das experiências com o desenho das disciplinas/aulas (E.DD), a interação professor-aluno (IPA), a interação alunoaluno (IAA), os processos de aprendizagem individual (PAI), e o resultado das disciplinas/aulas (E.RA), enquanto as variáveis dependentes são formadas pelos construtos de interesse do estudante (IE) e de satisfação (SAT).

Quadro 1 - Construtos e assertivas do instrumento da pesquisa

\begin{tabular}{|c|c|c|}
\hline Construtos & Itens do Instrumento & Referência \\
\hline \multirow{5}{*}{$\begin{array}{l}\text { Desenho da } \\
\text { disciplina } \\
\text { (E.DD) }\end{array}$} & $\begin{array}{l}\text { 1. O ambiente de aprendizado oferece fácil acesso a fórum, bate-papo, grupos } \\
\text { de notícias e/ou outros meios de comunicação para a interação com outros } \\
\text { participantes das aulas. }\end{array}$ & \multirow{5}{*}{$\begin{array}{c}\text { Paechter, } \\
\text { Maier e } \\
\text { Macher } \\
\text { (2010) }\end{array}$} \\
\hline & 2. Os materiais didáticos de cada aula são claros e bem estruturados. & \\
\hline & 3. O ambiente de aprendizagem é amigável. & \\
\hline & $\begin{array}{l}\text { 4. Muitas vezes, tenho que lidar com problemas técnicos (por exemplo, erros do } \\
\text { software, acesso lento à internet). }\end{array}$ & \\
\hline & $\begin{array}{l}\text { 5. A aula é exigente em relação à organização da aprendizagem e do tempo } \\
\text { necessário para a aprendizagem. }\end{array}$ & \\
\hline & $\begin{array}{l}\text { 6. Quando preciso de orientação do meu professor, posso entrar em contato } \\
\text { com ele facilmente via e-mail, chat, fórum etc. }\end{array}$ & $\begin{array}{l}\text { Paechter, } \\
\text { Maier e }\end{array}$ \\
\hline
\end{tabular}

RGO - Revista Gestão Organizacional, Chapecó, v. 14, n. 1, p. 356-377, jan./abr. 2021. 
Experiências com o ensino remoto e os efeitos no interesse e na satisfação dos estudantes de Ciências Contábeis durante a pandemia da SARS-CoV-2

\begin{tabular}{|c|c|c|}
\hline \multirow{6}{*}{$\begin{array}{l}\text { Interação } \\
\text { professor- } \\
\text { aluno (IPA) }\end{array}$} & $\begin{array}{l}\text { 7. Meu professor demonstra possuir muita experiência na implementação de } \\
\text { cursos/aulas de e-learning. }\end{array}$ & \multirow[t]{6}{*}{$\begin{array}{l}\text { Macher } \\
(2010)\end{array}$} \\
\hline & $\begin{array}{l}\text { 8. Meu professor fornece feedback rápido por outros recursos de comunicação, } \\
\text { como e-mail, bate-papo, grupos de notícias etc. }\end{array}$ & \\
\hline & $\begin{array}{l}\text { 9. Meu professor me apoia e me aconselha em relação aos meus processos de } \\
\text { aprendizado. }\end{array}$ & \\
\hline & 10. Sinto falta do contato pessoal com meu professor. & \\
\hline & $\begin{array}{l}\text { 11. As aulas à distância aumentam muito as relações pessoais via outros } \\
\text { dispositivos online. }\end{array}$ & \\
\hline & $\begin{array}{l}\text { 12. O bom uso da comunicação online minimiza a necessidade de contato } \\
\text { pessoal com o professor. }\end{array}$ & \\
\hline \multirow{5}{*}{$\begin{array}{l}\text { Interação } \\
\text { aluno-aluno } \\
\text { (IAA) }\end{array}$} & $\begin{array}{l}\text { 13. Eu posso trocar conhecimento de maneira fácil e rápida com outros } \\
\text { participantes das aulas por e-mail, chat, grupos de notícias etc. }\end{array}$ & \multirow{5}{*}{$\begin{array}{c}\text { Paechter, } \\
\text { Maier e } \\
\text { Macher } \\
\text { (2010) }\end{array}$} \\
\hline & $\begin{array}{l}\text { 14. Há muitas oportunidades nas aulas para estabelecer contato pessoal e/ou } \\
\text { eletrônico com outros alunos. }\end{array}$ & \\
\hline & $\begin{array}{l}\text { 15. As ferramentas de comunicação online facilitam o estabelecimento de novos } \\
\text { contatos com outros alunos. }\end{array}$ & \\
\hline & $\begin{array}{l}\text { 16. O aprendizado em grupos e a cooperação com outros alunos são promovidos } \\
\text { nas aulas (por exemplo, por atividades em grupo, discussões, etc.). }\end{array}$ & \\
\hline & $\begin{array}{l}\text { 17. O uso dos recursos de comunicação mediados por computador torna } \\
\text { complicado o trabalho em grupo. }\end{array}$ & \\
\hline \multirow{5}{*}{$\begin{array}{l}\text { Processos de } \\
\text { aprendizagem } \\
\text { individual } \\
\text { (PAI) }\end{array}$} & 18. Posso decidir por conta própria em que horários e onde estou aprendendo. & \multirow{5}{*}{$\begin{array}{l}\text { Paechter, } \\
\text { Maier e } \\
\text { Macher } \\
(2010)\end{array}$} \\
\hline & $\begin{array}{l}\text { 19. Posso decidir por conta própria sobre o ritmo da aprendizagem e o uso de } \\
\text { estratégias de aprendizagem. }\end{array}$ & \\
\hline & $\begin{array}{l}\text { 20. O ambiente de aprendizado (AVA) oferece oportunidades para aumentar } \\
\text { meu conhecimento e controlar meus resultados dos estudos (por exemplo, por } \\
\text { meio de de testes). }\end{array}$ & \\
\hline & $\begin{array}{l}\text { 21. Acho difícil me motivar e manter minha motivação para aprender durante as } \\
\text { aulas de forma e-learning (Reversa). }\end{array}$ & \\
\hline & $\begin{array}{l}\text { 22. Percebi um ganho de tempo com os estudos por meio das ferramentas } \\
\text { online. }\end{array}$ & \\
\hline \multirow{6}{*}{$\begin{array}{l}\text { Interesse do } \\
\text { estudante (IE) }\end{array}$} & 23. Você se sente interessado em aprender o conteúdo das disciplinas. & \multirow{6}{*}{$\begin{array}{c}\text { Paswam e } \\
\text { Young } \\
(2002) ; \\
\text { Vieira, } \\
\text { Milach e } \\
\text { Huppes } \\
\text { (2008) }\end{array}$} \\
\hline & 24. Geralmente, você fica atento na aula. & \\
\hline & 25. Você sente que as aulas Ihe desafiam intelectualmente. & \\
\hline & 26. Você acredita estar se tornando mais competente na sua área de estudo. & \\
\hline & 27. Geralmente, você participa de discussões quando instigado. & \\
\hline & 28. Avalio de forma positiva o meu desempenho ao longo das aulas. & \\
\hline \multirow{3}{*}{$\begin{array}{l}\text { Resultado das } \\
\text { aulas (E.RA) }\end{array}$} & 29. Conhecimentos e habilidades no assunto. & \multirow{3}{*}{$\begin{array}{c}\text { Paechter, } \\
\text { Maier e } \\
\text { Macher } \\
\text { (2010) }\end{array}$} \\
\hline & $\begin{array}{l}\text { 30. Competência (habilidades) pessoal (por exemplo, aprendizado } \\
\text { autorregulado). }\end{array}$ & \\
\hline & $\begin{array}{l}\text { 31. Competência na mídia (por exemplo, usando a Internet para a prática } \\
\text { científica). }\end{array}$ & \\
\hline \multirow{6}{*}{$\begin{array}{l}\text { Satisfação do } \\
\text { aluno (SAT) }\end{array}$} & 32. Sua satisfação geral com as disciplinas. & \multirow{6}{*}{$\begin{array}{l}\text { Vieira, } \\
\text { Milach e } \\
\text { Huppes } \\
\text { (2008) }\end{array}$} \\
\hline & 33. Sua satisfação geral com a sua Universidade. & \\
\hline & 34. De maneira geral, o curso atende as minhas expectativas. & \\
\hline & 35. Sua satisfação geral com o curso. & \\
\hline & 36. Sua satisfação geral com a modalidade e-learning (estudo dirigido). & \\
\hline & 37. Você recomendaria a modalidade e-learning para amigos. & \\
\hline
\end{tabular}

Fonte: dados da pesquisa (2020).

Em resposta às assertivas, exceto o bloco de dados demográficos, foi solicitado aos respondentes indicar seu grau de concordância com elas, considerando a escala tipo Likert de 
Edicreia Andrade dos Santos, Giulio Henrique Furlan de Campos, Jonatas Dutra Sallaberry e Luiz Miguel Renda dos Santos

5 pontos, variando de discordo totalmente ou totalmente insatisfeito (1) a concordo totalmente ou totalmente satisfeito (5).

O instrumento apresentou questões para controle das características amostrais, como gênero, idade, semestre letivo e tipo de vínculo profissional. Os estudantes foram instados a responder de forma textual e aberta suas contribuições para melhoria das aulas com apoio das ferramentas de TICs.

Antes da aplicação do instrumento de pesquisa, realizaram-se os procedimentos de back-translation (BRISLIN, 1980) com dois profissionais e um pré-teste (cinco professores e cinco estudantes), com vistas à validação externa. A partir do pré-teste, algumas questões dos instrumentos originais foram excluídas e outras tiveram suas redações adequadas ao idioma e ao contexto das estratégias de ensino. Por ocasião da coleta, foram assegurados o anonimato e as condições de guarda dos dados, sem identificação dos respondentes, bem como demais preceitos éticos de condução da pesquisa, conforme Termo de Consentimento e Livre Escolha, sendo que todos os participantes consentiram a participação na pesquisa.

\subsection{PROCEDIMENTOS DE ANÁLISE DOS DADOS}

A análise dos dados se deu em duas etapas. A primeira foi realizada a partir da técnica de modelagem de equações estruturais, estimada a partir dos Mínimos Quadrados Parciais (PLS-SEM), desenvolvido por Wold (1982 apud RINGLE; WENDE; BECKER, 2015). A técnica possibilita aferir uma série de equações de regressão múltipla separadas, mas interdependentes, de forma simultânea pela especificação do modelo estrutural (HAIR JR. et al., 2016). Sua aplicação se iniciou com a avaliação do modelo de mensuração e do modelo estrutural. As validações dos construtos decorreram de análises do algoritmo PLS, enquanto as relações estruturais, por meio do bootstrapping (HAIR JR. et al., 2016), ambas executadas pelo software SmartPLS 3.2.9.

Na segunda etapa, com vistas à aplicação da abordagem qualitativa para as respostas às perguntas abertas do instrumento de pesquisa, foi efetuada a análise de conteúdo (BARDIN, 2006). As categorias de análise se originaram da verificação das respostas de cada respondente, que, por conveniência, foram divididas por grupos de: considerações positivas; considerações negativas; métodos, técnicas, estratégias e aplicativos indicados pelos professores. Em cada grupo, foram detalhadas as subcategorias pelo agrupamento de respostas por termos ou significados semelhantes.

\section{ANÁLISE E DISCUSSÃO DOS RESULTADOS}

\subsection{ANÁLISE DESCRITIVA}

A análise descritiva dos dados permite conhecer as características da amostra da pesquisa. Assim, apresentam-se, na Tabela 1, os dados demográficos dos respondentes desta pesquisa. Observa-se pelos dados demográficos que a amostra é bastante heterogênea. Os respondentes são em sua maioria jovens, representados por $52 \%$ de estudantes com até 24 anos, demonstrando ser uma geração ambientada às tecnologias e à inovação. Embora não se vincule distinção de comportamento na presente pesquisa, na amostra respondente prevalecem estudantes do gênero masculino $(65,7 \%)$.

O grupo demonstra predominante experiência de vida a partir de vínculos profissionais e do ambiente acadêmico, ampliando a socialização do indivíduo. Na amostra destacam-se pessoas que exercem atividade laboral cotidianamente, como empregados em empresas 
Experiências com o ensino remoto e os efeitos no interesse e na satisfação dos estudantes de Ciências Contábeis durante a pandemia da SARS-CoV-2

privadas (39,2\%), órgãos públicos (20\%) e estagiários; somente $14,7 \%$ indicou não estar trabalhando.

Tabela 1 - Dados dos respondentes

\begin{tabular}{|c|c|c|c|c|c|}
\hline Gênero & $\mathrm{N}$ & (\%) & Idade & $\mathrm{N}$ & $(\%)$ \\
\hline Feminino & 35 & 34,3 & Menor de 21 anos & 25 & 24,5 \\
\hline Masculino & 67 & 65,7 & De 21 a 24 anos & 28 & 27,5 \\
\hline Total & 102 & $100 \%$ & De 25 a 30 anos & 24 & 23,5 \\
\hline Vínculo Profissional & $\mathrm{N}$ & $(\%)$ & Maior de 31 anos & 25 & 24,5 \\
\hline Autônomo/Empresário & 4 & 3,9 & Total & 102 & $100 \%$ \\
\hline Empregado & 40 & 39,2 & Semestre do Curso & $\mathbf{N}$ & $(\%)$ \\
\hline Estagiário & 23 & 22,6 & 3 e 4 & 18 & 17,6 \\
\hline Não está trabalhando & 15 & 14,7 & 5 e 6 & 38 & 37,3 \\
\hline Servidor público & 20 & 19,6 & 7 e 8 & 46 & 45,1 \\
\hline Total & 102 & $100 \%$ & Total & 102 & $100 \%$ \\
\hline
\end{tabular}

Fonte: dados da pesquisa (2020).

Em relação à experiência acadêmica, que é previamente estabelecida para estudantes desde o segundo semestre por conta da experiência organizacional, $45 \%$ dos respondentes declararam estar cursando o sétimo semestre ou mais. A maior experiência na instituição permite implicações não controladas na pesquisa, visto que maior tempo na IES possibilita maior familiaridade com as metodologias e correspondente à facilidade no manuseio das ferramentas.

De outra forma, esse maior avanço no período letivo propicia o desenvolvimento de hábitos e padrões de exigência, e as respostas obtidas podem incorporar respostas comparativas ao padrão da normalidade nos semestres anteriores. Esses fatores de possíveis vieses exigem a aplicação de testes estatísticos para, ao menos, validar os construtos e as variáveis, bem como as relações sustentadas na literatura consolidada.

\subsection{EQUAÇÕES ESTRUTURAIS - MODELO DE MENSURAÇÃO E MODELO ESTRUTURAL}

A análise do modelo de mensuração das equações estruturais é empregada para a avaliação da validade dos construtos, observando a validade discriminante e a validade convergente. A validade discriminante foi a primeira a ser verificada, sendo que dos 37 indicadores iniciais constantes do instrumento de pesquisa todos se demonstraram satisfatórios, com a maior carga no construto indicado. A análise da validade discriminante apontou as variáveis latentes do modelo, que, de acordo com Fornell e Larcker (1981), é confirmada quando o valor da raiz quadrada da Variância Média Extraída (AVE - Average Variance Extracted) é maior que os valores absolutos das correlações com as demais variáveis latentes. Assim, uma diagonal principal de correlação apresentou valores superiores às demais variáveis latentes, validando o desenvolvimento dos construtos.

No entanto, decorrente da análise da validade convergente, percebeu-se alguns construtos com cargas fatoriais menores do que o valor necessário, e, com isso, algumas variáveis precisaram ser excluídas, resultando em 33 variáveis restantes. As variáveis eliminadas foram as da experiência do desenho da disciplina (E.DD04, E.DD05), da interação professor-aluno (IPA10) e dos processos de aprendizagem individual (PAI21). O protocolo de adequação às validades convergentes, obtidas pelas observações das AVEs, com o critério de Fornell e Larcker (1981), propõe a aceitações de variáveis com valores das AVEs superiores a 0,5 .

Ringle, Silva e Bido (2014) destacam que a medida AVE é a porção dos dados (nas respectivas variáveis) que é explicada por cada um dos construtos ou da variável latente (VL), 
Edicreia Andrade dos Santos, Giulio Henrique Furlan de Campos, Jonatas Dutra Sallaberry e Luiz Miguel Renda dos Santos

referentes a seus conjuntos de variáveis ou a quanto, em média, as variáveis se correlacionam positivamente com os construtos concernentes ou com a VL. Os coeficientes da Validade Convergente, da Confiabilidade Composta e do Alfa de Cronbach apresentaram valores satisfatórios, a partir de 0,5, 0,7 e 0,7, respectivamente (FORNELL; LARCKER, 1981), evidenciados na tabela 2.

Tabela 2 - Validades do modelo

\begin{tabular}{|c|c|c|c|c|c|c|c|c|c|c|}
\hline \multirow{2}{*}{ Construtos } & \multirow{2}{*}{$\begin{array}{c}\text { Alfa de } \\
\text { Cronbach }\end{array}$} & \multirow{2}{*}{\begin{tabular}{|c|}
$\begin{array}{c}\text { Confiabilidade } \\
\text { composta }\end{array}$ \\
\end{tabular}} & \multirow{2}{*}{$\begin{array}{c}\text { Variância Média } \\
\text { Extraída (AVE) }\end{array}$} & \multicolumn{7}{|c|}{ Validade Discriminante } \\
\hline & & & & E.DD & IAA & IPA & PIA & E.RA & IE & SAT \\
\hline E.DD & 0,799 & 0,882 & 0,714 & 0.845 & & & & & & \\
\hline IAA & 0,717 & 0,822 & 0,573 & 0.664 & 0.757 & & & & & \\
\hline IPA & 0,845 & 0,885 & 0,564 & 0.798 & 0.670 & 0.751 & & & & \\
\hline PIA & 0,795 & 0,858 & 0,552 & 0.668 & 0.646 & 0.684 & 0.795 & & & \\
\hline E.RA & 0,912 & 0,945 & 0,852 & 0.707 & 0.653 & 0.630 & 0.725 & 0.923 & & \\
\hline IE & 0,884 & 0,913 & 0,639 & 0.668 & 0.596 & 0.628 & 0.660 & 0.824 & 0.799 & \\
\hline SAT & 0,894 & 0,918 & 0,655 & 0.667 & 0.617 & 0.639 & 0.686 & 0.749 & 0.697 & 0.809 \\
\hline
\end{tabular}

Fonte: dados da pesquisa (2020).

A análise da Tabela 2 evidencia que todas as cargas para a AVE se mostraram estatisticamente significativas, isto é, com valores iguais ou superiores a 0,5 (FORNELL; LARCKER, 1981). O indicador da Confiabilidade Composta atendeu aos valores limítrofes considerados satisfatórios, da mesma forma que os valores do Alfa de Cronbach - todos acima de 0,7 para as variáveis latentes.

Os indicadores de Confiabilidade Composta e Alfa de Cronbach satisfatórios sinalizam que a amostra está teoricamente livre de vieses, e que o instrumento de coleta de dados empregado é confiável (HAIR JR. et al., 2016). A apuração do Alfa de Cronbach foi para verificar a consistência interna dos resultados de cada variável latente (VL), que estabelece a expectativa de erro da medida feita, e quanto mais próximo de 1,00, menor a expectativa de erro e maior a confiabilidade do instrumento (HAIR JR. et al., 2016).

Na sequência, prosseguiu-se para a análise do modelo estrutural, que permite validar estatisticamente as relações entre os construtos e as conexões elaboradas, na forma estruturada de um diagrama de caminhos fundamentados na base teórica (HAIR JR. et al., 2016). Para mensurar a validade do modelo estrutural são analisados os critérios de tamanho e significância dos coeficientes de caminho e de determinação de Pearson $\left(R^{2}\right)$, por meio da técnica de Bootstrapping, e a Relevância Preditiva $\left(Q^{2}\right)$ na plataforma blindfolding, além dos tamanhos do efeito ( $\left.F^{2}\right)$ (HAIR JR. et al., 2016).

Inicialmente, decorrente da análise das cargas de caminhos, ainda que validados os construtos internamente, devido a uma carga ínfima, optou-se por excluir o item da variável de experiência da interação aluno-aluno (IAA17), considerada como contingência esperada em um ambiente de isolamento social. No bootstrapping, as subamostras foram criadas com observações retiradas aleatoriamente do conjunto original de dados (com substituição) e depois usadas para estimar o modelo de caminhos do PLS. Nesse caso, foram geradas 5.000 subamostras diferentes, como recomendado por Hair Jr. et al. (2016), cujos resultados são apresentados na tabela 3.

Esse procedimento foi realizado em duas etapas, sendo que na primeira foram avaliadas todas as relações de interesse, inclusive aquelas não significativas e que, consequentemente, não permitiram rejeitar a hipótese nula. A segunda foi realizada somente com os construtos que apresentaram significância estatística na primeira etapa, permitindo identificar a influência das relações validadas, ambas constantes na Tabela 3. 
Experiências com o ensino remoto e os efeitos no interesse e na satisfação dos estudantes de Ciências Contábeis durante a pandemia da SARS-CoV-2

Tabela 3 - Efeitos entre os construtos

\begin{tabular}{|c|c|c|c|}
\hline Relação Estrutural & Coef. & p-valor & Etapa \\
\hline Desenho da disciplina -> Interesse do estudante & 0,066 & 0,557 & \multirow[t]{10}{*}{1} \\
\hline Desenho da disciplina -> Satisfação & 0,103 & 0,398 & \\
\hline Interação aluno-aluno -> Interesse do estudante & 0,042 & 0,698 & \\
\hline Interação aluno-aluno -> Satisfação & 0,017 & 0,870 & \\
\hline Interação professor-aluno -> Interesse do estudante & 0,123 & 0,305 & \\
\hline Interação professor-aluno -> Satisfação & 0,121 & 0,309 & \\
\hline Processos de aprendizagem individual-> Interesse do estudante & 0,004 & 0,966 & \\
\hline Processos de aprendizagem individual-> Satisfação & 0,285 & $0,002 * *$ & \\
\hline Resultado das aulas -> Interesse do estudante & 0,669 & $0,000 * * *$ & \\
\hline Resultado das aulas -> Satisfação & 0,381 & $0,000 * * *$ & \\
\hline Resultado das aulas -> Interesse do estudante & 0,824 & $0,000 * * *$ & \multirow[t]{3}{*}{2} \\
\hline Resultado das aulas -> Satisfação & 0,466 & $0,000 * * *$ & \\
\hline Processos de aprendizagem individual-> Satisfação & 0,388 & $0,000 * * *$ & \\
\hline
\end{tabular}

Nota 1: $\mathrm{N}=102 .{ }^{* * *} \mathrm{p}<0,01 .{ }^{* *} \mathrm{p}<0,05$.

Nota 2: $Q^{2}=$ Interesse do estudante $(0,411)$; Satisfação $(0,372) \cdot F^{2}=$ Interesse do estudante $(2,122)$; Satisfação $(0,329) \cdot R^{2}=$ Interesse do estudante $(0,68)$; Satisfação $(0,63)$.

Fonte: dados da pesquisa (2020).

O valor de $Q^{2}$ do Stone-Geisser (STONE, 1974; GEISSER, 1974), como um critério de relevância preditiva, foi obtido por meio do procedimento blindfolding, uma técnica de reutilização da amostra, que, sistematicamente, exclui pontos e fornece um prognóstico dos seus valores originais (RINGLE; WENDE; BECKER, 2015). Para validação, os valores devem ser maiores que zero, e um modelo perfeito teria um valor igual a 1 (HAIR JR. et al., 2016), o que foi satisfeito.

A técnica preconiza que a técnica de análise por equações estruturais, quando há relevância preditiva, conjectura adequadamente os valores dos indicadores. $O \mathrm{~F}^{2}$ é uma medida que avalia se existe um impacto substancial sobre o construto dependente, quando um construto independente é omitido do modelo. Considerando os valores para $\mathrm{F}^{2}$ sugeridos por Hair Jr. et al. (2016), percebe-se grande efeito do modelo, assim, com a omissão do construto independente, haveria um impacto substancial nos construtos dependentes.

\subsection{DISCUSSÕES DAS HIPÓTESES}

A primeira hipótese buscou testar se as experiências do estudante com o desenho das disciplinas/aulas afetam positivamente (a) seu interesse enquanto estudante e (b) sua satisfação com a condução do curso, cujas relações não foram confirmadas. Por isso, não foi possível validar a primeira hipótese, em detrimento às evidências de Chang e Tung (2008) e Paechter, Maier e Macher (2010), obtidas em momentos de normalidade social. Dessa forma, pode-se atribuir tais discrepâncias ao processo de implantação do ensino remoto de forma contingencial por conta do isolamento social.

Esses achados podem evidenciar que a reprodução do ensino presencial no formato remoto não pode se resumir simplesmente a transmitir uma aula por alguma plataforma digital (Google Meet, por exemplo) com a turma, mas que existem outras metodologias de ensino e TICs para transferir as interações de uma sala de aula presencial para um ambiente virtual de aprendizagem. Uma possibilidade é mesclar a mediação da aprendizagem, combinando ferramentas síncronas e assíncronas, a fim de que os professores possam oferecer aos seus estudantes uma inovadora experiência no ensino remoto, mantendo a integração e o apoio ao discente, aliados à flexibilidade possível do material assíncrono (SANTOS JUNIOR; MONTEIRO, 2020). 
Edicreia Andrade dos Santos, Giulio Henrique Furlan de Campos, Jonatas Dutra Sallaberry e Luiz Miguel Renda dos Santos

A segunda hipótese proposta verificou se as experiências do discente com a interação professor-aluno afetam positivamente (a) seu interesse enquanto estudante e (b) sua satisfação com a condução do curso. Os resultados não confirmaram tais relações e ressaltam que embora fosse esperado que com o uso do AVA, em que a comunicação é instantânea, fossem facilitadas as interações entre estudantes e professores, gerando, assim, um aprendizado de maior proximidade, com exclusividade nas interações para o aluno, não foi o que se demonstrou.

Essas evidências refutam as proposições e os achados de Moore e Kearsley (2007) e Paechter, Maier e Machier (2010). Mesmo que as ferramentas tecnológicas ofertem canais de comunicação com exclusividade do docente ao discente, o que poderia ampliar o interesse e a satisfação do estudante, essas relações não foram validadas. Ainda que os professores mantenham fortes laços de confiança com os seus estudantes (MEDEIROS; SIQUEIRA, 2019), as críticas reveladas no processo de condução do ensino remoto podem ter afetado tais vínculos. Conforme demonstra-se no tópico seguinte, decorrente da mudança repentina e das contingências sociais, os docentes precisam responder muitas demandas a discentes e coordenação, em parte agravado pelos canais exclusivos que mitigam o ganho do saneamento de dúvidas por encontros presenciais e tempestivos com o grupo.

Os resultados da terceira hipótese não confirmaram a relação entre as experiências do aluno com a interação aluno-aluno afetando positivamente (a) seu interesse enquanto estudante e (b) sua satisfação com a condução do curso. Isso porque, neste período de isolamento social, as interações, em especial as face a face, não são possíveis, o que, de certo modo, reflete na qualidade e na quantidade de contatos. No entanto, esperava-se a confirmação dessa hipótese pelo fato de que uma das vantagens da inclusão dos AVAs no processo de ensino é que proporcionem uma maior interação entre os estudantes, por meio de fóruns de discussão e chats online.

Embora o estudante continue sendo um ser social, e que o ambiente tecnológico é propício para a interação entre os discentes, essa é uma realidade muito mais presente no cotidiano do que na época dos estudos elencados (MOORE; KEARSLEY, 2007; PAECHTER; MAIER; MACHER, 2010), podendo levar à desconsideração dessa relação quando se analisa o interesse e a satisfação do estudante. Outra possibilidade dessa ausência de validação da relação entre as variáveis decorre dos efeitos da implantação do ensino remoto contingencial, no qual os estudantes passaram a priorizar suas necessidades mais fundamentais, como acesso às plataformas, saúde e trabalho.

A quarta hipótese não corroborou a indicação de que a experiência com os processos de aprendizagem individual influencia positivamente 0 interesse do aluno $(\beta=0,004$; $p=0,966)$, mas confirmou o efeito positivo na satisfação do estudante $(\beta=0,285 ; p<0,01)$. Esse resultado demonstra que, apesar das contingências impostas em momentos de crise, que no caso do novo Coronavírus é o isolamento social, a estratégia de empregar o estudo dirigido como processo de aprendizado gerou satisfação no aluno, podendo relacionar-se aos processos cognitivo-construtivistas pessoais do indivíduo (YADIN; OR-BACH, 2019).

Essa estratégia incorpora elementos da variável de autonomia para decidir horários, ritmo de aprendizado, o que permite ao discente uma gestão mais adequada de seu tempo, reduzindo deslocamento e otimizando o estudo nos tópicos de maior dificuldade. Além disso o método de ensino é incorporado como estratégia ao ofertar a sala de aula (AVA) diretamente no local de estudo do discente, nas condições habituais, o que tende a suscitar maior conforto e prazer, reforçando os benefícios da aprendizagem autorregulada (NARCISS; PROSKE; KÖRNDLE, 2007; PINTRICH, 2000). 
Experiências com o ensino remoto e os efeitos no interesse e na satisfação dos estudantes de Ciências Contábeis durante a pandemia da SARS-CoV-2

A quinta hipótese ratificou a indicação de que a experiência com o resultado das aulas influencia tanto no interesse do estudante como na sua satisfação. Essa hipótese reforça o sentimento de utilitarismo, visto que o indivíduo desenvolve o interesse em um ambiente no qual tem resultados positivos. Independente dos efeitos de um isolamento social que diminua ou aumente os resultados das disciplinas/aulas, a relação é mantida.

A satisfação com os conhecimentos, as habilidades específicas da contabilidade e pessoais para autorregular o estudo e a competência com a mídia empregada geram maior interesse e participação do aluno (PAECHTER; MAIER; MACHER, 2010). Isso evidencia também que o aluno sente satisfação em alcançar o propósito de estar matriculado nos bancos acadêmicos, ou seja, sente-se realizado em estar desenvolvendo conhecimentos, competências e habilidades, mesmo em tempos de isolamento social. Apesar de ser uma lacuna temporal de muita restrição em todas as áreas, ainda assim a continuidade de capacitação e aquisição de competências promove satisfação pessoal, decorrente de processos emocionais (LEVY, 2007). Importante destacar que a satisfação engloba além do prazer do indivíduo com a utilidade alcançada, mas também maior interesse na continuidade dos estudos (LEVY, 2007). Os lapsos podem ser um obstáculo, mas em um momento em que a rotina sofreu forte impacto com mudanças, a continuidade, mesmo que limitada, demonstra-se como um fator relevante para evitar a evasão e propiciar um impacto social positivo a partir da educação profissional.

\subsection{ANÁLISE QUALITATIVA - OPINIÕES DOS ESTUDANTES}

As relações entre variáveis, ainda que mediante uma amostra suficiente, quando considerados coeficientes estatísticos, revelam a relação entre números, atribuindo suas implicações a percepções e crenças dos pesquisadores. O cotejamento das evidências quantitativas ocorre em tópico apartado, empregando a análise de conteúdo das respostas dos discentes.

Os respondentes, ao serem indagados acerca das indicações para melhoria das aulas com apoio das TICs, apresentaram diversas contribuições. Eles destacaram o papel principal do professor nas aulas, citando várias considerações com suas percepções e sugestões, conforme sintetizado na Figura 2.

Figura 2 - Nuvem de Palavras

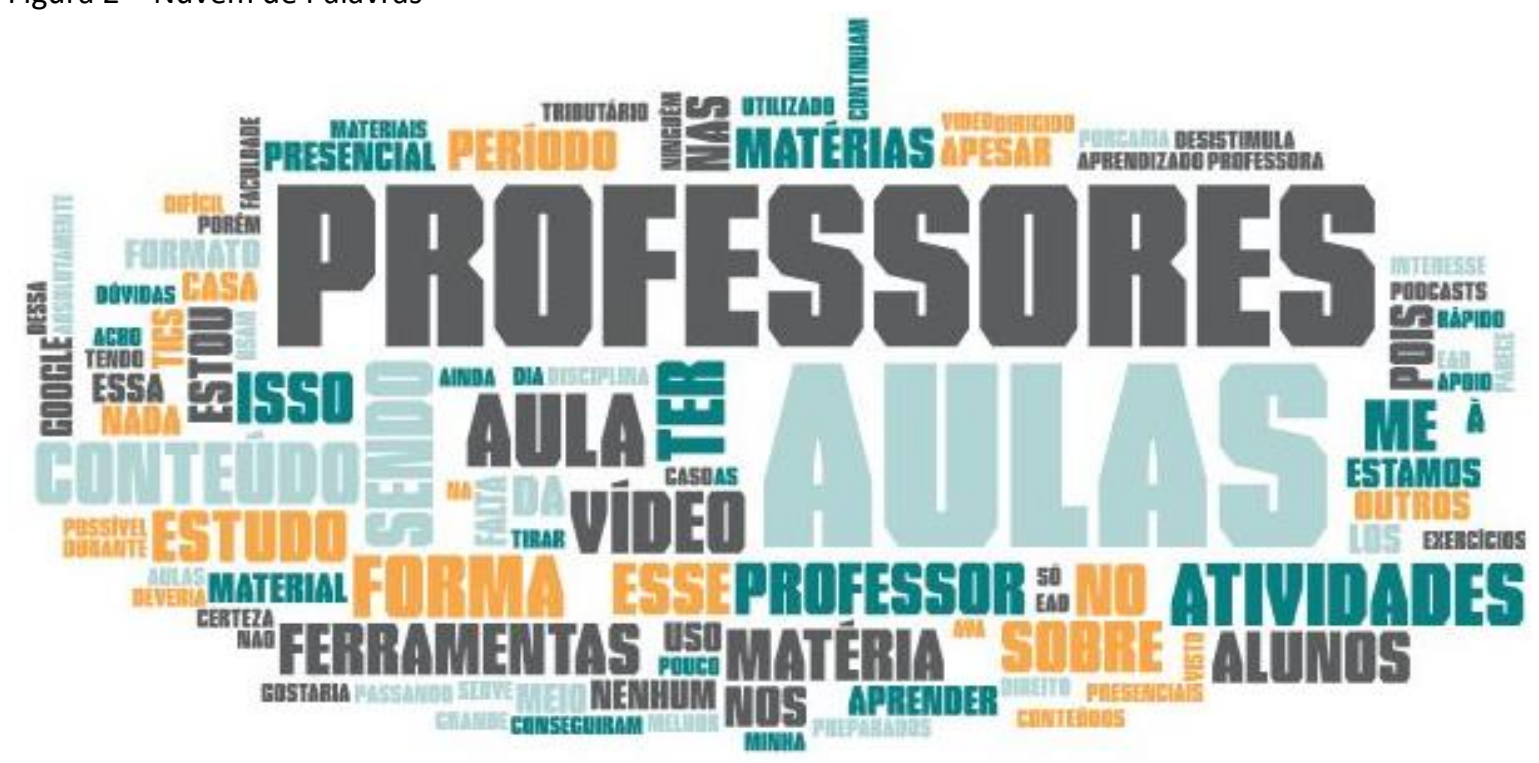

Fonte: dados da pesquisa (2020). 
Edicreia Andrade dos Santos, Giulio Henrique Furlan de Campos, Jonatas Dutra Sallaberry e Luiz Miguel Renda dos Santos

Esses comentários dos estudantes permitem uma visão mais ampla de suas impressões e crenças. As respostas foram divididas em três grupos de opiniões que emergiram dos dados: os métodos e os aplicativos sugeridos; as considerações positivas com reflexões e elogios; bem como as negativas, decorrente de falhas e dificuldades encontradas, que, em sentido inverso, apontam a oportunidade de melhoria. Transversalmente, foram categorizadas questões relacionadas especificamente às peculiaridades oriundas do isolamento social pela pandemia do SARS-CoV-2.

Quadro 2 - Percepções dos estudantes a respeito do ensino durante a pandemia de SARS-CoV-2

\begin{tabular}{|l|l|l|}
\hline $\begin{array}{c}\text { Métodos / Técnicas / } \\
\text { Estratégias / } \\
\text { Aplicativos }\end{array}$ & Considerações Positivas & \multicolumn{1}{c|}{ Considerações Negativas } \\
\hline - Aplicativo de & - Adaptação dos & \\
WhatsApp & professores & - Algumas disciplinas complexas \\
- Aula online síncrona & - Autodisciplina & - Ausência de calendário \\
- AVA & - Avaliação dos & - Baixa incorporação de recursos \\
- Google Class Room & professores & - Baixo estímulo aos discentes \\
- Google Meet & - Conteúdo & - Descontinuidade do conteúdo pré- \\
- Grupos de debate & complementar & isolamento \\
- Podcasts & - Professores habilitados & - Excesso de conteúdos e avaliações \\
- Slides & - Estruturação das aulas & - Falta de de feedbacks e tira-dúvidas \\
- Videoaulas & - Gestão do processo & - Falta de padronização de aplicativos entre \\
- YouTube & - Incorporação das TICs & os professores \\
& \multicolumn{2}{|l}{} \\
\hline
\end{tabular}

Fonte: dados da pesquisa (2020).

Os estudantes destacaram diversos pontos de discussão que são relevantes para o ensino em formato remoto, e suas peculiaridades de quando essa forma não é uma opção, mas a única alternativa à interrupção do ensino. Eles também mencionaram várias aplicações tecnológicas e estratégias online que os professores utilizam, algumas delas tradicionalmente empregadas em complemento ao ensino presencial, mas outras como alternativa aos encontros presenciais.

Além da disponibilização de slides de apresentações de aulas e do AVA, os estudantes relatam a utilização de vídeo aulas no AVA ou no YouTube, podcasts, grupos de discussão com o WhatsApp, o Google Class Room e o Google Meet. Essas aplicações de grupos de estudo online, de forma sincronizada, vão ao encontro da dificuldade citada quanto ao gerenciamento de tempo, visto que muitos dos estudantes que optam pela modalidade presencial informaram que a carga de atividades laborais e domésticas impedem sua dedicação ao estudo em casa.

A vinculação de um horário específico para os encontros otimizaria o isolamento ambiental para a atividade de estudo, viabilizando sua continuidade. Essa perspectiva pode ser ilustrada pelas percepções de dois respondentes:

E75: Seria de grande auxílio ter videoaulas durante o período em que está acontecendo as aulas [...] além de garantir o mesmo tempo mínimo dedicado àquela matéria por semana.

E93: [...] o uso das atividades somente por meio eletrônico me atrapalha, pois sou pai de família e o meu tempo em casa é preferencialmente dado a família, no meu caso acho inviáveis as aulas por meio eletrônico e me prejudica totalmente o envio de atividades por esse meio [...]. 
Experiências com o ensino remoto e os efeitos no interesse e na satisfação dos estudantes de Ciências Contábeis durante a pandemia da SARS-CoV-2

Os pontos positivos elencados pelos estudantes foram distintos, sintetizados na qualificação de parte dos professores no uso das TICs, na gestão do processo de ensino e na estruturação das aulas. Segundo os alunos, isso é importante porque grande parte do material já era usado de modo complementar às aulas presenciais e poderá continuar sendo utilizado, visto que alguns professores efetivamente incorporam as TICs na sua prática docente.

Os relatos indicam que o formato não presencial contribui com a autodisciplina porque o discente se obriga a destinar um tempo para essa atividade acadêmica. De certa forma, essa competência contrapõe a afirmação da necessidade de o encontro sincronizado devido às demandas pessoais impedirem tal dedicação. São questões contextuais, posto que há perfis distintos entre os estudantes, alguns com responsabilidades familiares, crianças, e outros não, o que implica diferentes percepções.

Os estudantes ressaltaram, de maneira significativa e positiva, a contribuição dos professores em adaptar os conteúdos para o formato online por ocasião da necessidade de isolamento social em tempos da pandemia, mesmo acarretando outras dificuldades. Esse foi um dos pontos mais importantes destacados, considerando a preocupação dos estudantes em não perder o semestre letivo. As reflexões de alguns respondentes podem ilustrar isso:

E16: Acredito que esteja sendo feito o possível mediante a situação que nos encontramos, peço que não interrompam o semestre, apesar das dificuldades vamos em frente!

E87: Fica aqui meu elogio à forma como (em grande parte) os professores se adaptaram rapidamente à realidade e conseguiram continuar ministrando os conteúdos.

Os pontos negativos apresentaram maior recorrência, conforme esperado, no entanto, tendem a centrar-se em itens comuns. Adotando como ponto de partida a habilitação dos professores, sinalizado também como ponto positivo, vislumbra-se que decorrem de experiências diversificadas, em diferentes disciplinas e com distintos docentes.

Enquanto professores, foram alvos de elogios e de críticas, pois, possivelmente, a habilidade para utilização de TICs esteja em níveis opostos. Esse problema direcionado aos docentes vai ao encontro das dificuldades relatadas pelos estudantes sobre a falta de apoio instrumental e de padronização de aplicações tecnológicas, porquanto cada docente utiliza uma aplicação distinta como estratégia de ensino. Percebe-se ser um problema atribuído a professores e estudantes que poderia ser mitigado pela instituição por meio de um help-desk, uma normativa ou um manual de procedimentos. Isso pode ser percebido no seguinte excerto:

E96: Os professores devem ter um auxílio (treinamento) para o conhecimento e utilização das TICS de forma eficaz, pois dá para se ter uma ideia de que eles não foram preparados para usá-las.

Também foram constatadas dificuldades em disciplinas que seriam mais complexas ou técnicas que, em conjunto com as demais disciplinas, resultam em déficit de aprendizado ou baixo desempenho, com consequente baixo estímulo do aluno. Alguns liames do problema decorrente da baixa qualificação docente no uso das TICs podem ser percebidos em outros itens de adversidade. Um exemplo de dificuldade que pode ter sido causado pela qualificação reduzida é a baixa incorporação de recursos tecnológicos, sendo que, algumas vezes, o ensino se limita ao envio de slides e questionários. A falta de feedback também é mencionada, visto que, no EaD, não existe a possibilidade do encontro periódico entre o aluno e o professor.

A ausência dessa interação, que ocorre no feedback e é importante para a comunicação das duas partes, conduz a outra constatação negativa, que é o excesso de 
Edicreia Andrade dos Santos, Giulio Henrique Furlan de Campos, Jonatas Dutra Sallaberry e Luiz Miguel Renda dos Santos

conteúdo e avaliações (por exemplo, questões), revelado com frequência entre os respondentes. Os comentários afirmam que esse fato pode se tornar latente entre aqueles estudantes com atividade laboral e deflagrar a ausência de competências, como a gestão do tempo. Os comentários de alguns respondentes ilustram isso:

E19: Gostaria de que os professores se atentassem a quantidade de material que está sendo fornecida, pois, apesar dessa quarentena, não são todos os alunos que ficam o dia inteiro em casa, e se todos passarem muito conteúdo fica difícil para os alunos que ainda continuam trabalhando durante esse período.

E28: Manter um equilíbrio em relação às atividades. Um mesmo ritmo.

Algumas das críticas anteriores são comuns à tipologia do ensino remoto no formato EaD e à causa pela qual muitos estudantes mantêm a preferência de escolha pelo ensino presencial. Todavia, essa mudança ocorreu devido a uma contingência que exigiu o afastamento social das pessoas. As alterações decorrentes do isolamento social na pandemia de SARS-CoV-2 também resultaram em algumas dificuldades pontuais, entre as quais a ausência do calendário letivo e a descontinuidade do conteúdo anterior.

De acordo com os relatos dos estudantes, eles não possuem conhecimento a respeito da programação de provas, algo que, possivelmente, seja construído consoante a evolução da pandemia no âmbito regional e as orientações técnicas dos órgãos de saúde. Outra queixa de alguns discentes ocorreu pela descontinuidade de alguns conteúdos pré-isolamento, o que pode prejudicar o desenvolvimento da disciplina e a formação do aluno.

Faz-se relevante destacar que a situação contingencial gerada pela pandemia de SARSCoV-2 causou prejuízos globais em termos sanitários, econômicos e sociais, e a solução das adversidades causa conflitos e divergências. No entanto, muitas dessas dificuldades são cotidianas, e o enfrentamento se dá dentro da normalidade habitual. Por fim, é interessante salientar um último relato:

E72: Os professores continuam os mesmos, mais ferramentas à disposição ajuda em vários sentidos, mas velhos problemas permanecem. O mesmo serve para os alunos, quem não se interessava, continua não se interessando e assim por diante.

\section{CONSIDERAÇÕES FINAIS}

Esta pesquisa teve como objetivo central analisar as experiências dos alunos de Ciências Contábeis com o ensino remoto implementado por uma IES federal da região centrooeste brasileira durante a pandemia. Ela possui como enfoque principal identificar os efeitos no interesse e na satisfação dos estudantes nas aulas e na condução do curso.

Os resultados frisaram as relações entre as variáveis em intensidade e significância estatística. Em momentos de normalidade, a evidências da literatura de referência indicam que o desenho da disciplina, a interação do estudante com os colegas e com o professor, os processos de aprendizagem e os seus resultados afetam positivamente o interesse e a satisfação do discente. Entretanto, o isolamento social como medida de proteção ao novo Coronavírus, que levou à adoção do ensino remoto contingencial, afeta o interesse do estudante e a satisfação com o curso, permitindo a validação como determinantes no modelo somente as variáveis de processos de aprendizagem individual e dos resultados das aulas.

Dentre as evidências, observou-se que é preciso que os professores busquem diferentes metodologias de ensino e distintas TICs para reproduzir uma sala de aula presencial em um ambiente virtual de aprendizagem, ou seja, é necessário pensar em um desenho instrucional diferenciado para que o estudante se envolva e tenha maior interesse e satisfação com as aulas. Ademais, como a maioria dos docentes e dos discentes desconhecia o 
Experiências com o ensino remoto e os efeitos no interesse e na satisfação dos estudantes de Ciências Contábeis durante a pandemia da SARS-CoV-2

funcionamento da dinâmica da modalidade de ensino remoto ou EaD, inúmeras dúvidas e receios tornaram-se salientes, refletindo nas experiências dos alunos com as interações entre professor-aluno e aluno-aluno, as quais interferem significativamente no processo de aprendizagem e, logo, no interesse e na satisfação do estudante. No entanto, é importante que os professores compreendam seu papel diante do processo educacional, não só usando tecnologias, mas permitindo que os recursos e as estratégias utilizadas possam incluir a todos os alunos, de forma a atender às necessidades educacionais específicas de cada um, acarretando, assim, maior interesse e satisfação individual.

Por ocasião do ensino remoto, os estudantes não validaram as influências decorrentes do desenho da disciplina, da interação do estudante com os colegas e com o professor. As disciplinas restritas a encontros "presenciais", por meio de um monitor somente, não demonstraram relação com o interesse e a satisfação. Os indícios demonstram que o meio virtual não deve ser subutilizado, carecendo do emprego eficaz das tecnologias disponíveis.

Distinto do esperado, a interação do estudante com seus pares e docentes não foi significativa para o interesse e a satisfação. Apesar dos relatos de maior contato, principalmente com os docentes, é possível que o excesso de demandas aos professores possa comprometer essa relação. Por outro lado, as tecnologias já empregadas no cotidiano dos estudantes os mantêm muito próximos em seus círculos de amizade, possivelmente mitigando os efeitos da falta de interação em classe.

A conexão entre as experiências com os processos de aprendizagem individual e a satisfação do estudante reforça a apreciação da estratégia de aprendizagem autorregulada, oriunda da maior autonomia discente para decidir horários, ritmo de aprendizado e local de estudo. Ainda mais relevante para a satisfação do estudante e, principalmente, para o seu interesse é o resultado alcançado por ele, reforçando o senso utilitarista em momento contingencial. Observou-se também a necessidade de adoção de sistemas de avaliação que reflitam o estado real de aprendizado dos estudantes, de técnicas e práticas pedagógicas que possibilitem maior interação professor-aluno e entre grupos de discentes no ensino remoto.

Percebe-se que o momento da pandemia de SARS-CoV-2 trouxe inúmeras incertezas e mudanças, mas permanece a situação do estudante como pessoa que está na universidade em busca de objetivos e metas para sua vida pessoal e profissional, enquanto o professor é um profissional procurando exercer da melhor forma sua função docente (JARDILINO; AMARAL; LIMA, 2010). Assim, estão juntos na busca por atingirem objetivos comuns, independentemente da contingência que os afete. Com isso, devem visar a uma contínua negociação pedagógica e criar uma ambiência de reciprocidade no processo de ensinoaprendizagem para que ambas as partes tenham boas experiências.

Esta investigação apresenta como limitação entre outras o aspecto temporal, pois a coleta de dados deu-se durante a ocorrência da pandemia e no transcorrer do ensino remoto pela IES, tempestivamente aos fatos, mas talvez sem o distanciamento necessário que a pesquisa científica carece. A não ampliação da amostra para outras IES federais que oferecem cursos de Ciências Contábeis e que adotaram desde o início da suspensão das aulas, sendo, em âmbito nacional, uma da região nordeste e outra da região sul brasileira, pode também ser considerada uma limitação.

Como sugestão para trabalhos futuros, recomenda-se, inicialmente, ampliar a amostra da pesquisa para cobrir os estudantes das outras IES que implantaram o ensino remoto desde o início da emergência sanitária, o que pode fornecer contribuições para um grupo mais abrangente, bem como com estudantes de IES que adotaram o ensino remoto na fase de declínio da pandemia. Também se sugere um estudo comparativo com docentes de IES 
Edicreia Andrade dos Santos, Giulio Henrique Furlan de Campos, Jonatas Dutra Sallaberry e Luiz Miguel Renda dos Santos

públicas e privadas que também implementaram o ensino remoto desde o início da pandemia de SARS-CoV-2.

\section{REFERÊNCIAS}

ABDOUS, M. Influence of satisfaction and preparedness on online students' feelings of anxiety. The Internet and Higher Education, v. 41, p. 34-44, 2019. DOI:

https://doi.org/10.1016/j.iheduc.2019.01.001.

ANDERSON, T. Towards a theory of online learning. Theory and practice of online learning.

2. ed. Edmonton: AU Press, 2004. p. 45-74.

BARDIN, L. Análise de conteúdo. São Paulo: Edições 70, 2006.

BRASIL. Ministério da Educação. Portaria n.o 4.059, de 10 de dezembro de 2004. Brasília, DF: MEC, 2004. Disponível em:

http://portal.mec.gov.br/sesu/arquivos/pdf/nova/acs_portaria4059.pdf. Acesso em: 5 maio 2020.

BRASIL. Ministério da Educação. Portaria n.o 873, de 7 de abril de 2006. Brasília, DF: MEC, 2006. Disponível em: http://portal.mec.gov.br/sesu/arquivos/pdf/portarias/portaria873.pdf. Acesso em: 5 maio 2020.

BRASIL. Ministério da Educação. Portaria n.o 343, de 17 de março de 2020. Brasília, DF: MEC, 2020. Disponível em: http://www.in.gov.br/en/web/dou/-/portaria-n-343-de-17-de-marcode-2020-248564376. Acesso em: 5 maio 2020.

CHANG, S. C.; TUNG, F. C. An empirical investigation of students' behavioural intentions to use the online learning course websites. British Journal of Educational Technology, v. 39, n. 1, p. 71-83, 2008. DOI: https://doi.org/10.1111/j.1467-8535.2007.00742.x.

COSTA, O. S.; GOUVEIA, L. B. Modelos de Retenção de Estudantes: Abordagens e Perspectivas. REAd - Revista Eletrônica de Administração, Porto Alegre, v. 24, n. 3, p. 155182, 2018. DOI: http://dx.doi.org/10.1590/1413-2311.226.85489.

DENG, S. Q.; PENG, H. J. Characteristics of and public health responses to the coronavirus disease 2019 outbreak in China. Journal of clinical medicine, v. 9, n. 2, p. 575, 2020. DOI: https://doi.org/10.3390/jcm9020575.

DIAS, E.; PINTO, F. C. F. A Educação e a Covid-19. Ensaio: aval. pol. públ. Educ., Rio de Janeiro, v. 28, n. 108, p. 545-554, 2020. DOI: https://doi.org/10.1590/s010440362019002801080001.

EHLERS, U. D. Quality in e-learning from a learner's perspective. European Journal of Open, Distance and E-learning, v. 7, n. 1, 2004. 
Experiências com o ensino remoto e os efeitos no interesse e na satisfação dos estudantes de Ciências Contábeis durante a pandemia da SARS-CoV-2

FAUL, F.; ERDFELDER, E.; BUCHNER, A.; LANG, A. G. Statistical power analyses using G* Power 3.1: Tests for correlation and regression analyses. Behavior research methods, v. 41, n. 4, p. 1149-1160, 2009. DOI: https://doi.org/10.3758/BRM.41.4.1149.

FORNELL, C.; LARCKER, D. F. Evaluating structural equation models with unobservable variables and measurement error. Journal of marketing research, v. 18, n. 1, p. 39-50, 1981. DOI: https://doi.org/10.1177/002224378101800104.

GEISSER, S. A predictive approach to the random effect model. Biometrika, v. 61, n. 1, p. 101-107, 1974. DOI: https://doi.org/10.1093/biomet/61.1.101.

GUERREIRO, E. M. B. R. Avaliação da satisfação do aluno com deficiência no ensino superior: estudo de caso da UFSCar. 2011. $231 \mathrm{f}$. Tese (Doutorado em Educação Especial) Universidade Federal de São Carlos: São Carlos, 2011.

HAIR JR., J. F. ; HULT, T. M. ; RINGLE, C. ; SARSTED, M. A primer on partial least squares structural equation modeling (PLS-SEM). New York: Sage publications, 2016.

JARDILINO, J. R. L.; AMARAL, D. J.; LIMA, D. F. A interação professor-aluno em sala de aula no ensino superior: o curso de administração de empresas. Revista Diálogo Educacional, Curitiba, v. 10, n. 29, p. 101-119, 2010. DOI: http://dx.doi.org/10.7213/rde.v10i29.3064.

KOLOGRIVAYA, E.; SHLEIFER, E. Quarantined: China's Online Education in the Pandemic. The Diplomat. 26 mar. 2020. Disponível em: https://thediplomat.com/2020/03/quarantinedchinas-online-education-in-the-pandemic/. Acesso em: 1 maio 2020.

LEVY, Y. Comparing dropouts and persistence in e-learning courses. Computers \& education, v. 48, n. 2, p. 185-204, 2007. DOI: https://doi.org/10.1016/j.compedu.2004.12.004.

MEDEIROS, B. N.; SIQUEIRA, M. V. S. Relações de Confiança e sua Instrumentalização no Controle de Docentes em IES Privadas. REAd - Revista Eletrônica de Administração, Porto Alegre, v. 25, n. 1, p. 213-237, 2019. DOI: https://doi.org/10.1590/1413-2311.241.90087.

MOORE, M. G.; KEARSLEY, G. Educação a distância. São Paulo: Thomson Learning, 2007.

MORTARI, A. D. A Construção Cotidiana da Greve na Ufrgs: o Movimento Contra as Reformas no Final de 2016. REAd - Revista Eletrônica de Administração, Porto Alegre, v. 25, n. 3, p. 278-296, 2019. DOI: https://doi.org/10.1590/1413-2311.273.97261.

NARCISS, S.; PROSKE, A.; KOERNDLE, H. Promoting self-regulated learning in web-based learning environments. Computers in human behavior, v. 23, n. 3, p. 1126-1144, 2007. DOI: https://doi.org/10.1016/j.chb.2006.10.006.

NEWS WIRES. Covid-19: Older school children should wear masks, French science council says. France24. 26 abr. 2020. Disponível em: https://www.france24.com/en/20200426french-middle-and-secondary-school-students-and-staff-should-wear-masks-science-council. Acesso em: 1 maio 2020. 
Edicreia Andrade dos Santos, Giulio Henrique Furlan de Campos, Jonatas Dutra Sallaberry e Luiz Miguel Renda dos Santos

OLIVEIRA, J. B. A.; GOMES, M.; BARCELLOS, T. A Covid-19 e a volta às aulas: ouvindo as evidências. Ensaio: aval. pol. públ. Educ., Rio de Janeiro, v. 28, n. 108, p. 555-578, 2020. DOI: https://doi.org/10.1590/s0104-40362020002802885.

PAECHTER, M.; MAIER, B.; MACHER, D. Students' expectations of, and experiences in elearning: Their relation to learning achievements and course satisfaction. Computers \& Education, v. 54, n. 1, p. 222-229, 2010. DOI:

https://doi.org/10.1016/j.compedu.2009.08.005.

PASWAN, A. K.; YOUNG, J. A. Student evaluation of instructor: A nomological investigation using structural equation modeling. Journal of Marketing Education, v. 24, n. 3, p. 193-202, 2002. DOI: https://doi.org/10.1177/0273475302238042.

PINTRICH, P. R. Multiple goals, multiple pathways: The role of goal orientation in learning and achievement. Journal of educational psychology, v. 92, n. 3, p. 544, 2000. DOI: https://doi.org/10.1037/0022-0663.92.3.544.

RINGLE, C. M.; SILVA, D.; BIDO, D. S. Modelagem de equações estruturais com utilização do SmartPLS. Revista Brasileira de Marketing, São Paulo, v. 13, n. 2, p. 56-73, 2014. DOI: https://doi.org/10.5585/remark.v13i2.2717.

RINGLE, C. M.; WENDE, S.; BECKER, J. M. SmartPLS 3. Boenningstedt: SmartPLS GmbH. 2015.

SANTOS JUNIOR, V. B.; MONTEIRO, J. C. Educação e Covid-19: as Tecnologias Digitais Mediando a Aprendizagem em Tempos de Pandemia. Revista Encantar-Educação, Cultura e Sociedade, Bom Jesus da Lapa, v. 2, p. 1-15, 2020. DOI:

https://doi.org/10.46375/encantar.v2.0011.

SHARPE, R.; BENFIELD, G. The student experience of e-learning in higher education. Brookes eJournal of Learning and Teaching, v. 1, n. 3, 2005.

SILVA, T. J. S.; FREITAS, M. M.; SALLABERRY, J. S.; FLACH, L. Academic performance and the level of use of metacognitive self-regulatory learning strategies by accounting students. In: American Accounting Association - Annual Meeting, 2019, San Francisco. Anais eletrônicos [...]. San Francisco: AAA, 2019.

SOARES, J. R.; BORDIN, R.; ROSA, R. S. Indicadores de Gestão e de Qualidade nas Instituições Federais de Ensino Superior Brasileiras, 2009-2016. REAd - Revista Eletrônica de Administração, Porto Alegre, v. 25, n. 2, p. 215-239, 2019. DOI: https://doi.org/10.1590/1413-2311.250.95100.

STONE, M. Cross-validation and multinomial prediction. Biometrika, v. 61, n. 3, p. 509-515, 1974. DOI: https://doi.org/10.1093/biomet/61.3.509.

UNESCO. COVID-19 Educational disruption and response. UNESCO, 2020. Disponível em: https://en.unesco.org/covid19/educationresponse. Acesso em: 29 abr. 2020. 
Experiências com o ensino remoto e os efeitos no interesse e na satisfação dos estudantes de Ciências Contábeis durante a pandemia da SARS-CoV-2

VIEIRA, K. M.; MILACH, F. T.; HUPPES, D. Equações estruturais aplicadas à satisfação dos alunos: um estudo no curso de ciências contábeis da Universidade Federal de Santa Maria. Revista Contabilidade \& Finanças, São Paulo, v. 19, n. 48, p. 65-76, 2008. DOI: http://dx.doi.org/10.1590/S1519-70772008000300006.

WATSON, J.; THOMPSON, C. Covid-19: Virus forced US schools online, but many students didn't follow. The Star. 20 abr. 2020. Disponível em: https://www.thestar.com.my/tech/tech-news/2020/04/20/covid-19-virus-forced-usschools-online-but-many-students-didnt-follow. Acesso em: 1 maio 2020.

YADIN, A.; OR-BACH, R. The importance of emphasizing individual learning in the "collaborative learning era". Journal of Information Systems Education, v. 21, n. 2, p. 5, 2019. 